\section{IMPACT OF RANDOMISED TRIAL EVIDENCE AND ESC GUIDELINE CHANGE ON PRACTICE OF PREVENTIVE PCI IN PATIENTS WITH ST-ELEVATION MYOCARDIAL INFARCTION}

${ }^{1}$ Steven Hadyanto*, ${ }^{2}$ Miles Curtis, ${ }^{1}$ David Wald. ${ }^{1}$ Barts and The London School of Medicine and Dentistry; ${ }^{2}$ Barts Health NHS Trust

10.1136/heartjnl-2019-BCS.61

Introduction In 2012, European Society of Cardiology (ESC) guidelines advised against performing PCI in non-infarct arteries (preventive PCI) in patients with ST-elevation myocardial infarction, STEMI (Level III recommendation). With the publication of several randomised trials showing a benefit of preventive PCI in such patients, ESC guidelines changed (to Level IIb in 2014 and IIa in 2017) and now advise that preventive PCI should be considered either immediately or during a second "staged" procedure. We sought to examine whether the changing evidence has led to a change in practice.

Methods We used electronic hospital records to identify all patients treated for STEMI at the Barts Heart centre, London between 2012 and 2018. Patients with cardiogenic shock were excluded. We examined procedure reports to identify those with multivessel disease $(>50 \%$ stenosis in one or more noninfarct arteries) who had infarct-artery PCI only or infarctartery plus preventive PCI, either immediately or as a staged procedure. We recorded the number and proportion of STEMI patients receiving preventive PCI over time and used regression analysis to determine any significant trends.

Results Among the 3355 patients with STEMI without cardiogenic shock who underwent PCI during the 5 years 20122018, 1786 (53\%) had multivessel disease. Of these, 1245 (70\%) received PCI to the infarct artery only and 541 (30\%) also received preventive PCI. The Figure shows the number and proportions of patients receiving preventive PCI in each year, together with the publication date for randomised trials and ESC guideline publications. Use of preventive PCI increased by 5.6 percentage points $(95 \%$ Confidence interval $1.7 \%-9.6 \%$ ) per year ( $p$ for trend=0.017).

Conclusion The results show a steady increase in the use of preventive PCI in patients with STEMI, following the publication of randomised trials showing the benefits of preventive PCI and ESC guidance recommending its use.

\section{REFERENCES}

1. Wald DS, Morris JK, Wald NJ, et al. Randomized Trial of Preventive Angioplasty in Myocardial Infarction. N Engl J Med 2013;369:1115-1123.

2. Gershlick AH, Khan JN, Kelly DJ, et al. Randomized trial of complete versus lesion-only revascularization in patients undergoing primary percutaneous coronary intervention for STEMI and multivessel disease: the CvLPRIT trial. J Am Coll Cardiol 2015;65(10):963-72.

3. Engstrøm $\mathrm{T}$, Kelbæk $\mathrm{H}$, Helqvist $\mathrm{S}$, et al. Complete revascularisation versus treatment of the culprit lesion only in patients with ST-segment elevation myocardial infarction and multivessel disease (DANAMI-3-PRIMULTI): an open-label, randomised controlled trial. Lancet 2015;386(9994):665-71.

4. Smits PC, Abdel-Wahab M, Neumann FJ, et al. Fractional Flow Reserve-Guided Multivessel Angioplasty in Myocardial Infarction. N Engl J Med 2017:376 (13):1234-1244

5. The Task Force on the management of ST-segment elevation acute myocardial infarction of the European Society of Cardiology (ESC). ESC Guidelines for the management of acute myocardial infarction in patients presenting with ST-segment elevation. Eur Heart J 2012:33:2569-2619.

6. The Task Force on Myocardial Revascularization of the European Society of Cardiology (ESC) and the European Association for Cardio-Thoracic Surgery (EACTS). 2014 ESC/EACTS Guidelines on myocardial revascularization. Eur Heart J 2014;35:2541-2619.

7. The Task Force for the management of acute myocardial infarction in patients presenting with ST-segment elevation of the European Society of Cardiology (ESC). 2017 ESC Guidelines for the management of acute myocardial infarction in patients presenting with ST-segment elevation. Eur Heart J 2018;39:119-177.

Conflict of Interest None

\begin{tabular}{l}
\hline 64 \\
PRIMARY PCI IN THE VERY ELDERLY: A RETROSPECTIVE \\
STUDY OF OUTCOME IN PATIENTS AGED 85 YEARS \\
AND OVER UNDERGOING EMERGENCY ANGIOGRAPHY \\
IN A SCOTTISH REGIONAL CATHETERISATION \\
LABORATORY CENTRE 2013-2018
\end{tabular}

George Reid, Louise Aubiniere-Robb* ${ }^{*}$ Aengus Murphy. ${ }^{~}$ NHS Lanarkshire

\subsection{6/heartjnl-2019-BCS.62}

Introduction Primary PCI (PPCI) as management for acute STEMI is an established evidence based treatment offered across the UK. Evidence of benefit in the very elderly is sparse. With an aging population, the demand on primary PCI

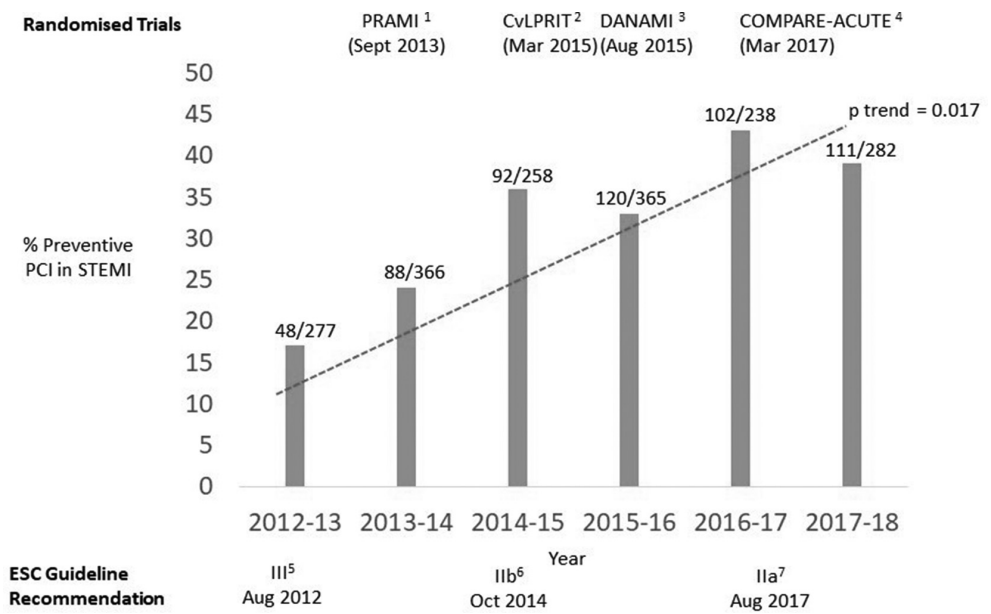

Abstract 63 Figure 1 Proportion of patients with STEMI without cardiogenic shock receiving Preventive PCI by year 2012-2018 (Key randomised trials and ESC Recommendations marked). 